Original Research Article

\title{
A study on adverse drug reactions of oral anti-diabetic agents in patients with type II diabetes mellitus in Hi-Tech Medical College and Hospital, Bhubaneswar, Odisha, India
}

\author{
Indrani Dey*, Srikanta Mohanty, Anju Prasad, Chaitali Patnayak, Ratna Palit
}

Department of Pharmacology, Hi-Tech Medical College and Hospital, Bhubaneswar, Odisha, India

Received: 22 January 2019

Revised: 06 April 2019

Accepted: 12 April 2019

\section{*Correspondence to: \\ Dr. Indrani Dey, \\ Email: indranideyyy@ \\ gmail.com}

Copyright: (C) the author(s), publisher and licensee Medip Academy. This is an openaccess article distributed under the terms of the Creative Commons Attribution NonCommercial License, which permits unrestricted noncommercial use, distribution, and reproduction in any medium, provided the original work is properly cited.

\begin{abstract}
Background: Diabetes mellitus is an emerging non communicable, life style disease \& the use of anti-diabetics has been increasing. Adverse drug reactions (ADRs) are well known to occur with any class of drugs when used in normal doses for the management of diseases. Anti-diabetic agents are no exception to this. The study of ADRs is the concern of the field known as pharmacovigilance. The objective of the present study was to analyze and describe the patterns of adverse events associated with the use of oral Anti-diabetic agents

Methods: A hospital based prospective observational study at Hi-Tech Medical College and Hospital, Bhubaneswar, Orissa. Convenience samples of 266 adult patients, prescribed with oral anti-diabetic agents from October 2016 to November 2018 were selected, out of which 74 patients developed ADRs. Data collected from available prescriptions. The severity assessment is done using the Hartwig and Siegal scale and preventability assessment using modified Schumock and Thornton is done.

Results: Study suggests that female predominance in $41(55.40 \%)$ patients with maximum cases of $43.24 \%$ in age group of $61-70$ years age group. Maximum ADRs reported related to endocrine system seen in $36(48.67 \%)$ patient population. Sulfonylureas $38(51.35 \%)$ shows the largest numbers of ADR. The maximum ADRs reported were probable (56.73\%). The severity assessment using the Hartwig and Siegal scale indicated that the majority of the ADRs were $63(81.63 \%)$ as mild cases respectively.

Conclusions: This study has provided evidence of monitoring and detecting ADRs and their management through therapeutic interventions which is beneficial in the better patient outcome.
\end{abstract}

Keywords: ADRs, Anti-diabetic agents, Diabetes, Hartwig and Siegal scale, Pharmacovigilance

\section{INTRODUCTION}

Diabetes mellitus is an emerging non communicable, life style disease, mainly characterized by hyperglycemia caused by defective insulin secretion, resistance to insulin action, or a combination of both . Adverse drug reactions (ADRs) are well known to occur with any class of drugs when used in normal doses for the management of diseases. Anti-diabetic agents are no exception to this. ${ }^{1}$

According to the World Health Organization (WHO), ADRs is defined as a response to a drug which is noxious and unintended, and which occurs at doses normally used in man for the prophylaxis, diagnosis or therapy of disease, or for the modification of physiological function. This definition excludes overdose, drug abuse, and treatment failure and drug administration errors. ${ }^{2,3}$

ADRs are considered as one of the most important leading causes of mortality in many countries. ADR not only accounts for significant morbidity and mortality but can also lead to increase in the length of hospital stay and healthcare costs. 
ADR is one of the main governing factor which affects patients compliance and drug adherence. ADRs can occur in all settings where healthcare is provided. ADRs are a significant public health problem in the world. Not only do ADRs cause death and injury but they also affect the duration of treatment which in turn leads to increased healthcare costs and decreased patient productivity. ${ }^{4,5}$

The study of ADRs is the realm of what is known as pharmacovigilance. The WHO defines pharmacovigilance as "the science and activities relating to the detection, assessment, understanding, and prevention of ADRs or any other drug-related problems." It can help in providing continuous information on the safety of drug used. ${ }^{6}$

The increase in the prevalence of anti-diabetic medications highlights the need for the importance of clinical pharmacist for monitoring and reporting any suspected ADRs. To detect and analyze the ADRs in patients with diabetes mellitus with an assessment of causality, severity, and preventability in Hi-Tech Medical College \& hospital, the study has been carried out.

The aim was to evaluate and monitor the adverse drug reactions (ADRs) associated with oral diabetics agents in OPD patients of type II diabetes mellitus.

\section{METHODS}

The design of this study was a hospital based prospective observational study conducted at the Medicine ward of Hitech Medical College and Hospital, Bhubaneswar, Orissa between October 2016 to November 2018 (2 years). The sample size of 74 cases.

\section{Inclusion criteria}

- Patients of both sex and age ranging from 20 years and above.

- Newly diagnosed and known cases of diabetes were also included in the study.

\section{Exclusion criteria}

- Gestational diabetes mellitus,

- $\quad$ Type 1 diabetes mellitus and with co-morbidities

The ethical committee clearance was obtained from the institutional ethical committee .Purpose of the study were explained before to the respondents. Verbal consent was taken from the respondent before data collection. Privacy and confidentiality were maintained.

\section{Tools and instruments}

Patient data was recorded in the standard case record form. The suspected drug reactions were recorded in the ADR documentation form designed as per need of the study for evaluation.

\section{Sampling method and data collection}

When suspected ADRs were detected, they were brought to the notice of the concerned physician for confirmation on drug-induced reactions. All the identified ADRs were assessed by using causality, severity, and preventability scales. The causality assessment of the reported ADRs was carried out using the 'Naranjo causality assessment scale' or ADR probability scale which is a questionnaire based scoring system ranging from 0 to 9 . The total score calculated from this questionnaire defines the category as possible (1-4), probable (5-8), and definite ( $\geq 9)$.

The severity assessment of the reported ADRs as mild, moderate, and severe was determined according to 'Hartwig severity scale.' According to this scale, ADRs were assessed as mild (level 1,2), moderate (level 3, 4, 5), and severe (level 6,7). The preventability of an ADR was determined by "modified Schumock and Thornton preventability Scale." This scale assesses and categorizes ADRs into definitely preventable, probably preventable, or not preventable. The results were analyzed using descriptive statistics. Age group, gender, drugs involved, type of drug reactions, management of ADRs, causality, severity, and preventability were presented in proportions

\section{Statistical analysis}

MS Excel 2007 and SPSS v.-20 were used for the statistical analysis. The results are expressed to evaluate the association with different variables and to draw the inference.

\section{RESULTS}

Total enrolled patients were 266 of which 74 developed ADR, Incidence of ADRs occurrence to anti diabetic drugs, was higher in $41(55.41 \%)$ were female and $33(44.59 \%)$ were male shown in Table 1.

Table 1: Distribution of ADRs to antidiabetic drugs on gender difference.

\begin{tabular}{|lll|}
\hline Gender & No. & $\%$ \\
\hline Male & 33 & 44.59 \\
\hline Female & 41 & 55.41 \\
\hline Total & 74 & 100 \\
\hline
\end{tabular}

Table 2: Age distribution of patients developing ADR.

\begin{tabular}{|lll|}
\hline Age & NO. of patients & $\%$ \\
\hline $20-30$ & 2 & 2.71 \\
\hline $31-40$ & 5 & 6.75 \\
\hline $41-50$ & 12 & 16.22 \\
\hline $51-60$ & 18 & 24.33 \\
\hline $61-70$ & 32 & 43.24 \\
\hline 70 and above & 5 & 6.75 \\
\hline Total & 74 & 100 \\
\hline
\end{tabular}


The majority of the ADRs occurred in the age group were seen in elderly patients (61-70 yr age group) about $43.24 \%$, 32 ADRs) followed by $24.33 \%$ (18 ADRs) in the age group between 51-60 yr age group, $16.22 \%$ (12 ADRs) between $41-50 \mathrm{yr}$ age group and $6.75 \%$ (5 ADRs) between 31 and 40 year, shown in Table 2.

Table 3: Distribution of ADR on monotherapy and combination therapy.

\begin{tabular}{|lll|}
\hline Drug therapy & No. & $\%$ \\
\hline Mono therapy & 31 & 40.98 \\
\hline Combination therapy & 43 & 57.02 \\
\hline Total & 74 & 100 \\
\hline
\end{tabular}

Out of 74 patients developing ADR while receiving anti diabetic therapy $31(40.98 \%)$, were receiving monotherapy and $43(57.02 \%)$ were receiving combination therapy, shown in Table 3.

\section{Table 4: Most common ADR developed related to} systems on antidiabetic drugs.

\begin{tabular}{|lll|}
\hline ADRs of different system & No. & $\%$ \\
\hline Endocrine system & 36 & 48.67 \\
\hline GI system & 29 & 39.18 \\
\hline Skin and appendages & 4 & 5.40 \\
\hline CNS & 2 & 2.70 \\
\hline Musculoskeletal & 3 & 4.05 \\
\hline Total & 74 & 100 \\
\hline
\end{tabular}

As per SOC, the most commonly seen ADRs were related to endocrine system particularly hypoglycaemia, weight gain $(n=36,48.64 \%)$ and gastrointestinal system $(n=29$, $39.18 \%)$, particularly loss of appetite $(n=8)$, and epigastric pain $(n=7)$ and flatulence $(n=8)$ loose stool $(n=6)$ of the total ADRs were observed. Besides these, ADRs related to skin and appendages $(n=4,5.40 \%)$, musculoskeletal $(n=2$, $2.70 \%)$, CNS particularly dizziness in $(n=3,4.05 \%)$, shown in Table 4.

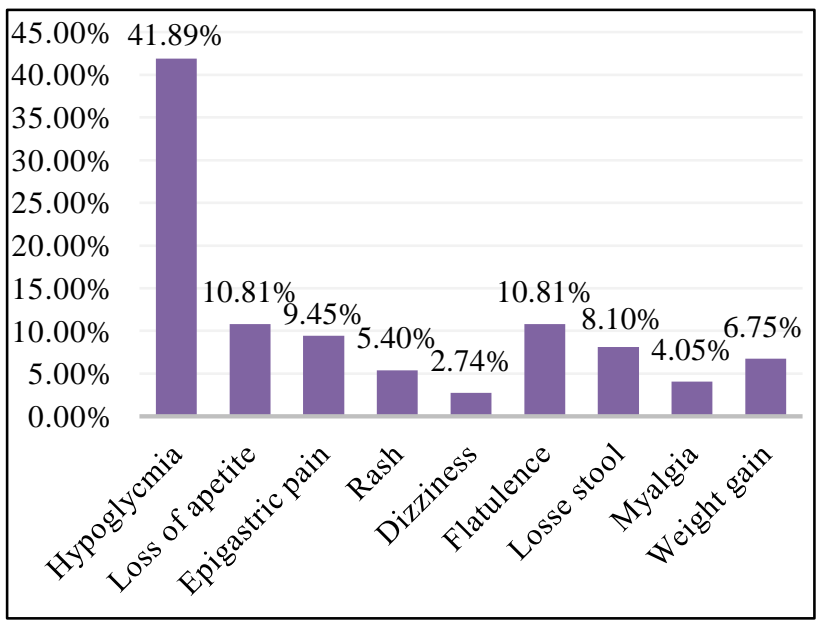

Figure 1: Distribution of nature of different adverse effects with different drug use.
Frequency of nature of ADR is maximum in case of hypoglycaemia with 31 cases $(41.89 \%)$, followed by flatulence and loss of appetite with $10.81 \%$ cases. 5 patients $(6.75 \%)$ complained of weight gain. Besides this there are only few cases came up with complaints of rashes and itching in $4(5.40 \%)$, dizziness in $2(2.70 \%)$ and myalgia and body ache in $3(4.05 \%)$, shown in Figure 1.

Table 5: ADRs shown on treatment with different classes of antidiabetics.

\begin{tabular}{|lll|}
\hline ADRs due to different class & No. & $\%$ \\
\hline Biguanides & 22 & 29.73 \\
\hline Sulfonylureas & 38 & 51.35 \\
\hline TZD & 11 & 14.86 \\
\hline Alpha-glucosidase inhibitor & 2 & 2.71 \\
\hline Dpp4 inhibitor & 1 & 1.35 \\
\hline Total & 74 & 100 \\
\hline
\end{tabular}

In present study the class of drugs most commonly responsible for causing maximum ADRs is associated with sulfonylureas in 38 cases $(51.35 \%)$, followed by 22 (29.73\%) cases with biguanides. Other cases of ADRs associated with TZDs 11 (14.86\%) and $2.71 \%$ with alpha glucosidase inhibitor. Least cases of ADRs seen with therapeutic class of DPP4 with $1.35 \%$ respectively, shown in Table 5.

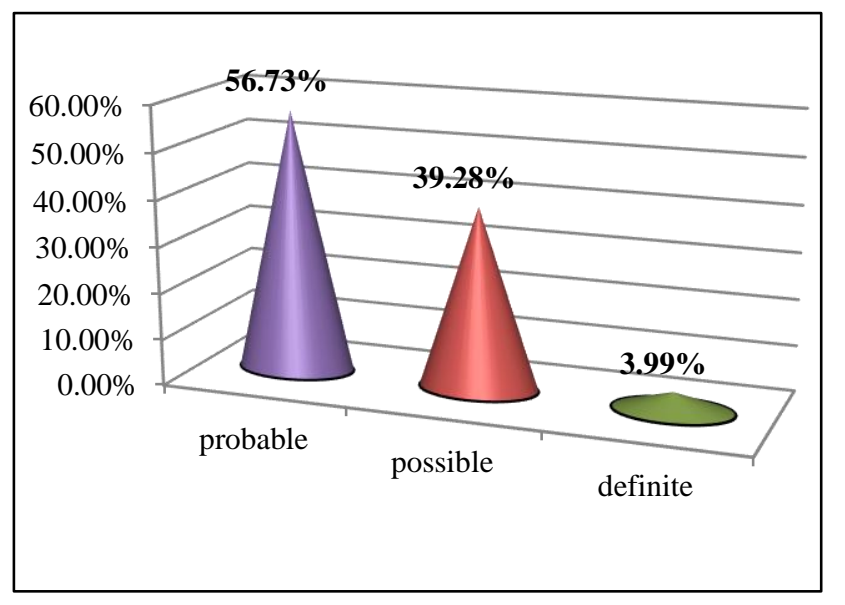

Figure 2: ADRs assessment according to Naronjo scale.

According to Naronjo scale $(56.73 \%)$ ADRs were probable, (39.28\%) were possible, and (3.99\%) were definite shown in Figure 2.

The ADRs were assessed for their severity using a modified Hartwig severity scale, which is a standard scale for severity assessment. Severity assessment of ADRs showed, out of 74 ADR cases collected, 21 (28.37\%) ADRs as moderate, and $53(73.63 \%)$ as mild. None of the cases fall under severe category as per our study, showed in Figure 3. 


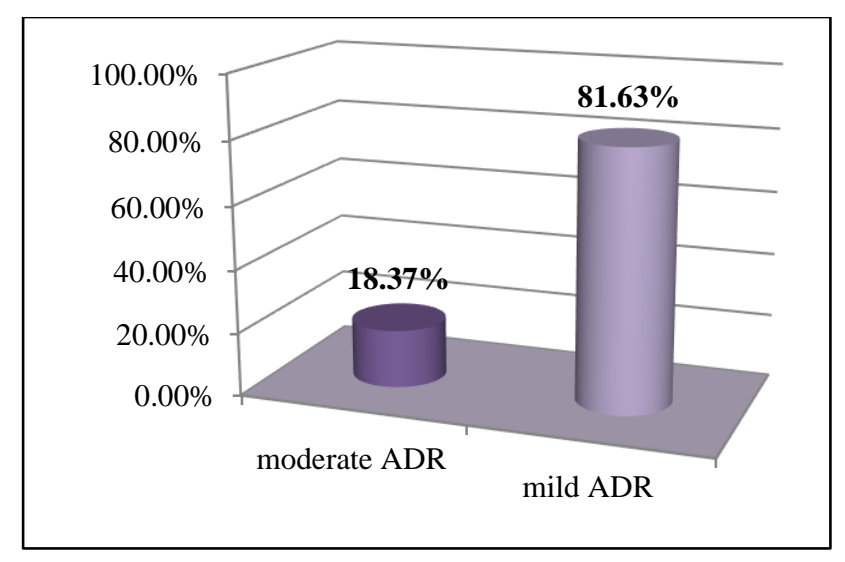

Figure 3: Distribution of severity assessment using modified Hartwig and Siegel's scale.

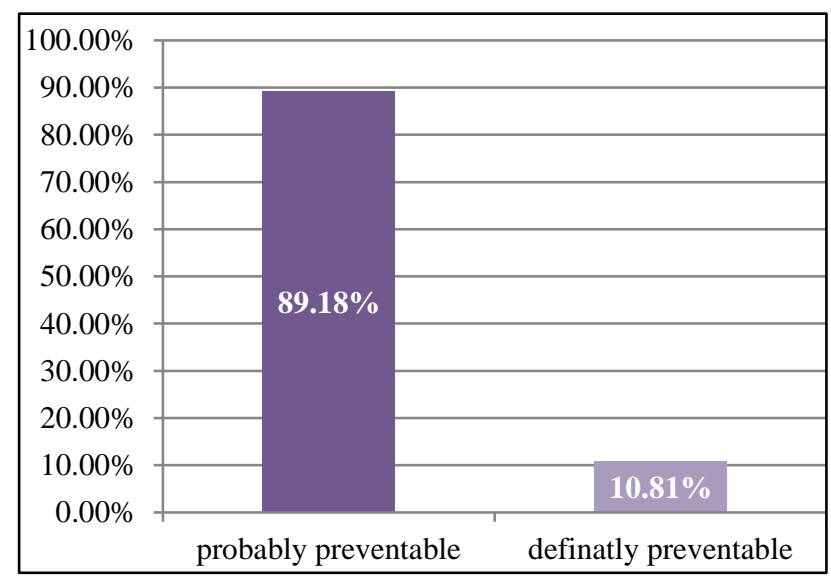

Figure 4: Management and prevention of ADRs according to modified Schumock and Thornton preventability scale.

Preventability of the reported ADRs was assessed using the "modified Schumock and Thornton preventability scale." Using this scale, results revealed that 66 (89.18\%) were probably preventable while $8(10.81 \%)$ were definitely preventable and no cases falls under not preventable category shown in Figure 4.

Table 6: Distribution of patients according to management of ADRs.

\begin{tabular}{|lll|}
\hline Treatment & No. Of ADRs $(\mathbf{n = 7 4})$ & $\%$ \\
\hline Drug changed & 8 & 10.81 \\
\hline Drug withdrawn & 3 & 4.05 \\
\hline $\begin{array}{l}\text { Symptomatic } \\
\text { treatment }\end{array}$ & 20 & 27.04 \\
\hline No change & 11 & 14.86 \\
\hline Dose altered & 17 & 22.97 \\
\hline Specific treatment & 15 & 20.27 \\
\hline
\end{tabular}

Considering the management of the reported ADRs, the majority of the ADRs around 20 cases $(27.04 \%)$ managed by symptomatic treatment followed by specific treatment in $20.27 \%$ and in $22.97 \%$ of the cases the dose has been altered of the suspected drug showed in Table 6.

\section{DISCUSSION}

ADR monitoring can help in providing continuous information on the safety of drug used. The increase in the prevalence of anti-diabetic medications highlights the need for the importance of physicians for monitoring and reporting any suspected ADRs. This study is done to detect and analyze the ADRs in patients with diabetes mellitus with an assessment of causality, severity, and preventability.

In present study as recorded, out of 74, 62.16\% were female and $37.84 \%$ were male, similar to the study conducted by Rao et al and Dilip et al. ${ }^{7,8}$ The predominance of female developing ADRs may be due to gender related differences in pharmacokinetics, immunology and hormonal factors. It may require rational dose adjustment to minimize the incidence of ADR., ${ }^{7,8}$

In this study it was reflected that, the higher percentage (43.24\%) of ADRs were developed in the age group of 61$70 \mathrm{yrs}$. The result of present study is very close to study carried by Rajesh et al, and Pirmohamed et al, study which showed maximum ADRs are in geriatric age group which described that age has linear relationship with developing of ADRs. ${ }^{9,10}$

This might be because advance age plays risk factor due to pharmacodynamic and pharmacokinetic changes which together with impairment of homeostatic mechanisms and coexisting underlying comorbidities such as hypertension, renal failure, myocardial infarction, heart failure, and dyslipidemia, which forces them to receive multiple drug therapy and leading to significant increase in the incidence of ADRs. One important finding in the present study revealed that patients receiving combination therapy $(57.02 \%)$ ADRs have predominance over mono-therapy $(40.98 \%)$. Similar result was also found in Roy K et al, and Pizzimenti $\mathrm{V}$ et al. Unwanted drug interaction may be one of the important factors behind the development of this type of ADRs. It is known that multiple drug therapy and co-morbidities predispose patients to ADRs. ${ }^{11,12}$

In present study, endocrine system ( $48.67 \%$ ) was the most common system associated with ADRs, followed by gastrointestinal system $(39.18 \%)$ this result was in association with Palaniswamy et al, where endocrine system was affected most. In this study few ADR cases also involved with musculoskeletal system, CNS and skin. ${ }^{13}$ The different types of ADRs were developed due the different patterns of prescription of different types of anti diabetic drugs by different physicians. Hypoglycaemia was the most common individual ADR which was encountered in $41.89 \%$ of the patients which was similar to the study done by Kulkarni et al. No episode of hypoglycemia exhibited marked severity i.e. loss of consciousness or immediate requirement for medical assistance. Though CV 
diseases is the main leading cause of morbidity and mortality among diabetic patients, but such ADR is not reported in my study. ${ }^{14}$

Among the various classes of anti-diabetic drugs used sulfonylureas is the commonest drug developed ADRs $(51.35 \%)$, followed by biguanides $(29.73 \%)$. This trend goes in parallel to studies done by Nirojini PS et al. ${ }^{15}$

In this study DPP4 inhibitors showed least (1.35\%) ADRs may be due to the fact that these group of drugs prescribed much less in numbers to patients or due to high efficacy and lesser side effects.

In present study metabolic abnormalities like hypoglycaemia due to sulfonylureas and GI problems mainly like loss of appetite, epigastric pain, loose motion due to metformin and few cases of allergic reactions because of glibenclamide are the maximum kind of ADRs seen.

To strengthen and further emphasize the validity of the study, causality assessment was done using Naranjo's scale.

According to Naronjo scale in my study $56.73 \%$ were probable and $39.28 \%$ were possible and definite is least that is $3.99 \%$. These findings are similar to the study carried out by Patidar et al. Definite is least due to rechallenge is not possible. ${ }^{16}$

On the evaluation of the severity of ADRs in my study by the Hartwig and Siegel severity assessment scale, it was evident that most of the ADRs reported in my study were $82 \%$ mild in nature and none of the cases were severe. No lethal outcomes were observed or produced during the study period.

This is similar to the study conducted by Rajesh et al, which showed that majority of the ADRs were mild followed by moderate. Also, these findings are in accordance with Vijayakumar et al, where $77 \%$ \& $68 \%$ mild reactions were recovered. ${ }^{17}$

In present study assessment of the preventability of the ADRs is done by using modified Schumock and Thornton scale, it was evident that $89.18 \%$ were probably preventable and $10.81 \%$ are defiantly preventable, similar to result conducted by Dilip C et al, where $90 \%$ ADRs were probably preventable, and contrast to study conducted by Patidar et al, which showed around 45\% ADRs falls under not preventable category. Mostly are found probably preventable as few necessary laboratory tests not performed or preventative measures not prescribed when administering drug to patient. ${ }^{8,16}$

Management is either done by either withdrawn the drug, altering the drug dosage dosage, or giving symptomatic treatment.
The outcomes of the suspected reactions showed that study subjects recovered from the reactions. Severity and outcomes were correlated, most of the mild reactions showed faster recovery when compared to moderate reactions.

\section{CONCLUSION}

ADR is mostly seen in geriatric age group with maximum cases related to metabolic disorders and GI disorders, mostly $80 \%$ ADR belong to mild category, of them maximum of the cases recovered mainly by symptomatic treatment.

So, this study results provide insight to the healthcare providers on the importance of monitoring and reporting of ADRs especially in elderly patients with diabetes mellitus who might suffer significant deleterious effects associated with the drugs. The active involvement of physicians for detecting and monitoring ADRs and their management through therapeutic interventions would be beneficial in the better patient outcome. This study also reflects that ADRs affected mostly to endocrine system \& GI system.

By implementing such programs could lead to a reduction in the incidence of ADRs. The early detection and management of adverse reactions can reduce health and economic burden on patients, and it also improves patients adherence and enhances health surveillance.

Funding: No funding sources

Conflict of interest: None declared

Ethical approval: The study was approved by the Institutional Ethics Committee

\section{REFERENCES}

1. Powers AC. Diabetes mellitus. In: Longo DL, Kasper DL, Jameson JL, Fauci AS, Hauser SL, Loscalzo J. Harrison's principle of internal medicine. 18th ed. New York: McGraw Hill; 2012:2968-3002.

2. The WHO Adverse event Terminology-WHO-ART, Terminology for coding clinical information in relation to drug therapy. Available at: http://www.umc-products.com/graphics/3149.pdf .

3. Available at: https://www.who-umc.org/globalpharmacovigilance/global-pharmacovigilance/

4. World Health Organization International drug monitoring: The role of national centres. Tech Rep Set WHO 1972. No. 498. Geneva: WHO. Available at: https://apps.who.int/iris/handle/10665/40968

5. Edwards IR, Aronson JK. Adverse drug reactions: definitions, diagnosis, and management. Lancet. 2000;356(9237):1255-9.

6. Pharmacovigilance Programme of India (PvPI) for Assuring Drug Safety. Available at: http://cdsco.nic.in/pharmacovigilance_intro.htm.

7. Rao PG, Archana B, Jose J. Implementation and results of an adverse drug reactions reporting 
programme at an Indian teaching hospital. Indian $\mathbf{J}$ Pharmacol. 2006;38:2936.

8. Dilip C, Mani LM, Saraswathi R. Adverse drug reactions monitoring in tertiary level referral hospital, Perinthalmanna, Kerala. Indian J Hosp Pharm. 2011;48:107-1.

9. Rajesh R, Ramesh M, Parthasarathi G. A study on adverse drug reactions related hospital admission and their management. Indian J Hosp Pharm. 2008;45:143-8.

10. Pirmohamed M, James S, Meakin S, Green C, Scott AK, Walley TJ, et al. Adverse drug reactions as cause of admission to hospital: Prospective analysis of 18 , 820 patients. BMJ. 2004;329(456):15-9.

11. Roy K, Divya S, Nadig P, Prakash B. Monitoring and analysis of adverse drug reaqctionsina private tertiary care teaching hospital. Asian J Pharm Clin Res. 2015;8(2):335-7.

12. Pizzimenti V, Ientile V, Fava G, Giudice I, Bonfiglio C, Alecci U, et al. Adverse reactions with anti-diabetic drugs: Results from a prospective cohort study in Sicily, 2015. Available at: http://www.congresso.sifweb.org/archivio/cong36/ab s/379.pdf.

13. Padmaja SY, Palaniswamy S. A study on assessment, monitoring and documentation of adverse drug reactions. Int J Pharm Teachnol Pract. 2012;3(2):2536.
14. Kulkarni GP, Patil LV. Analysis of adverse drug reactions spontaneously reported to adverse drug monitoring centre of a tertiary care hospitalprospective study. Int J Curr Pharm Res. 2018;10:235 .

15. Nirojini PS, Yemineni R, Nadenla RR. Monitoring and reporting of adverse drug reactions in a South Indian tertiary care hospital. Int J Pharm Sci Rev Res. 2014;24:259-62.

16. Patidar D, Rajput MS, Nirmal NP, Savitri W. Implementation and evaluation of adverse drug reaction monitoring system in a tertiary care teaching hospital in Mumbai, India. Interdiscip Toxicol. 2013;6(1):41-6.

17. Vijayakumar TM, Dhanaraju MD. Description of adverse drug reactions in a multi-speciality teaching Hospital. Int J Integr Med. 2013;1(26):1-6.

Cite this article as: Dey I, Mohanty S, Prasad A, Patnayak C, Palit R. A study on adverse drug reactions of oral anti-diabetic agents in patients with type II diabetes mellitus in Hi-Tech Medical College and Hospital, Bhubaneswar, Odisha, India. Int $\mathbf{J}$ Basic Clin Pharmacol 2019;8:837-42. 